\title{
Relationship between the Personality and Gender and the Adjustment to a Foreign Culture: Comparative Research between Expatriates and Business Trip Travelers
}

\author{
Hana Ornoy ${ }^{1}$, Goni Levi- Nishri ${ }^{2} \&$ Liad Uziel $^{2}$ \\ ${ }^{1}$ School of Business Administration, The Lander Academic Institute, Jerusalem, and Department of Economics and \\ Management, The Open University, Rahanana, Israel \\ ${ }^{2}$ Psychology Department, Bar-Ilan University, Ramat-Gan, Israel \\ Correspondence: Hana Ornoy, School of Business Administration, The Lander Academic Institute, Am Veholamo \\ Street 3, Jerusalem, and Department of Economics and Management, The Open University, 108 Ravutski Street, \\ Rahanana 43107, Israel. E-mail: hanaru@openu.ac.il
}

Received: March 8, 2014

doi:10.5430/ijba.v5n3p122

\author{
Accepted: March 22, 2014 \\ Online Published: May 6, 2014 \\ URL: http://dx.doi.org/10.5430/ijba.v5n3p122
}

\begin{abstract}
The research examines how personality characteristics and gender influence adjustment to a foreign culture among workers participating in one of two international assignment types: expatriation and frequent business trips. The research presents first evidence of relationships between personality and adjustment among business travelers, joins previous findings of relationships between personality characteristics and adjustment to a foreign culture among expatriates, and enables comparison between the two assignment types. The research contributes new findings on differences between the sexes in global employment: men adjust better than women to a foreign culture in the two assignment types, in two of four dimensions examined.

The research examines how personality characteristics and gender influence adjustment to a foreign culture among workers participating in one of two international assignment types: expatriation and frequent business trips. The research presents first evidence of relationships between personality and adjustment among business travelers, joins previous findings of relationships between personality characteristics and adjustment to a foreign culture among expatriates, and enables comparison between the two assignment types. The research contributes new findings on differences between the sexes in global employment: contrary to our hypothesis, men adjust better than women to a foreign culture in the two assignment types, in two of four dimensions examined.
\end{abstract}

Keywords: personality, gender, adjustment, expatriates, business trip travelers

\section{Introduction}

1.1 In past decades it is possible to see growth both in the number of organizations that send workers on international assignments and in the number of workers from every organization who go on such assignments (Tay, Westman, \& Chia, 2008). International assignments are expressed in two main formats: expatriate assignments and frequent business travels. Expatriation is the old method and is more known and researched. This method describes a situation in which a worker is sent to a foreign country for a lengthy period (a number of years) by the organization in which he is employed for a long-term goal (Huang, Chi, \& Lawler, 2005). The traditional format of international assignments through expatriation was joined by a new format of short assignments - frequent business trips. One of the reasons is the attempt to cope with the disadvantages that exist in the method of classic expatriate assignment, such as high costs and adjustment difficulties of family members (Morley \& Heraty, 2004). In this method, the worker continues to live in his mother country and to work in the familiar home organization but he travels frequently to a foreign country or to foreign countries so as to perform short assignments.

One of the greatest challenges of workers on international assignments is to cope with cultural barriers in the destination country. To act effectively and to succeed in the assignment, the worker must adjust his behaviors so that they will fit the host culture (Huang et al., 2005). Previous research studies linked the worker's level of adjustment to his level of performances on the international assignment (Raduan, Subramaniam, Jegak, \& Naresh, 2010) and found that workers who adjust well have more available psychological resources, which help them in the expatriate 
assignment (Shaffer, Harrison, Gilley, \& Luk, 2001). For example, established relationships were found between personality characteristics and adjustment to a foreign culture among workers sent for long expatriate assignments (Huang et al., 2005; Lee \& Sukoco, 2008). However, a research has yet to be performed that examines the relationship between personality characteristics and adjustment to a foreign culture among workers who go on short and frequent business trips in the framework of their job.

Another topic that inspires interest in the field of international assignments but has not been investigated in-depth is the difference in the level of adjustment between men and women who are sent to assignments overseas. For the most part, men are more involved in these assignments, but the number of women who take part in the global arena has risen over the years, and accordingly the research interest in them has also increased (Altman \& Shortland, 2008).

This work examines the relationship between the personality characteristics and gender (each one separately) and the adjustment to a foreign culture among Israeli workers who take part in international assignments in different countries around the world. The present research is a pioneer research that may shed light on the nature of the relationship between personality and adjustment among workers who go for frequent business trips, unlike other research studies that addressed only the relationship between personality characteristics and expatriation. While most of the research studies in the field of international assignments focus only on one of the formats (expatriation or business trips), the second contribution of the present research is the ability to examine the relationships that were noted in a comparative manner between the two types of international assignments. Another contribution is a comparative research between men and women in the context of adjustment to a foreign culture. This is unlike other research studies that focused for the most part on one of the genders or did not differentiate between them.

\subsection{Theoretical Background and Research Hypotheses}

\subsubsection{Expatriate Assignment}

Many workers assigned to foreign countries positively view the international experience, from explanations of expression of interest in the specific assignment, high salary, and good benefits (such as private schools for the children), adventure and curiosity about a foreign culture (Sussman, 2011). However, conversely, mobility of workers to work in a foreign country is a process that is difficult and complex for the worker, since he must quickly adopt the cultural contexts inside and outside of his workplace. The new challenges include language barriers, lack of proficiency in the local customs, lack of familiarity with the management culture in the company where the expatriate has been assigned, and loss of the support network existing in the origin country. Many expatriates cope with tension, anxiety, hostility, powerlessness, and depression. The expatriate experience has even been compared in the past to a general trauma that the expatriate experienced, when the cultural hints and expectations, as he knew them, are no longer commensurate with his new reality (Sussman, 2011).

In the past decade there has been a sharp rise in the phenomenon of expatriate assignments. However, the estimate is that $16 \%-40 \%$ of the expatriates do not finish the assignment and return to their home countries early. An organization invests considerable resources in sending a family on assignment overseas, and frequently the money is wasted since the expatriate or members of his family did not adjust to the new culture (Ornoy \&Tarba, 2011). In addition to this cost, lack of success in the assignment can even influence the continuation of the system of relations between the organization and the host country (Caligiuri, 2000). The expatriate also may suffer many damages in a case of failure, including harm to his confidence and self-esteem, decline in the level of appreciation on the part of his peers, and harm to the relations in the family (Ornoy \& Tarba, 2011). Even in cases in which a worker completes his assignment, it is not clear whether it was effective (Sussman, 2011). Many expatriates remain in their position for the defined period of time, although in actuality they do not function effectively and thus cause damages to the organization, such as reduction in the output and harm to the company's image. Expatriate effectiveness, therefore, depends largely on the expatriates' level of adjustment to the host country (Harvey \& Novicevic, 2001). Therefore, it is not surprising that many research studies chose to focus on the issue of the adjustment to a foreign culture among expatriates (for example, Caligiuri, 2000; Huang et al., 2005).

\subsubsection{Frequent Business Trips}

In the framework of this international assignment, the family is divided - the worker is sent to a foreign country and is there alone, while the members of his family remain in the home country (Westman, 2004). One of the goals of business travel is to deal with the disadvantages that exist in the classic expatriate assignment method, such as high costs, difficult adjustment of family members, and concern for the continuation of the career that accompanies both spouses (Morley \& Heraty, 2004). The short international assignments are considered more suited to the new, 
technological, global, accessible, and linked world (Demel \& Mayrhorfer, 2010), and like with the phenomenon of expatriate assignment, the scope of such business trips has increased over the years (Tay, Westman, \& Chia, 2008). Thus, for example, it was found that in the period 1982-2007 the number of citizens in England who were involved in business trips outside of England grew by $277 \%$ and was estimated at more than nine million travelers, while the number of workers from foreign countries who came to England in the framework of business travel also rose by $270 \%$ and was estimated at almost one million workers (Beaverstock et al., 2009).

Demel and Mayrhofer (2010) in their research conducted interviews with Austrian managers who tend to travel on frequent business trips to different countries in Europe. The interviews showed that the managers noted positively the implications of the trips on their careers, since they saw them as opportunities to advance, to learn, and to develop. In contrast, in terms of implications on their private lives and wellbeing, the managers described a negative and difficult picture. Research studies showed that, one the one hand, there are advantages for the frequent business trip traveler, such as visiting different countries and cultures and thus broadening horizons and understanding of intercultural differences (Beaverstock et al., 2009) but on the other hand, there are disadvantages. There are negative physical effects such as long and uncomfortable trips in planes and the phenomenon of jet lag, which induce tiredness and physical exhaustion (DeFrank, Konopaske, \& Ivancenich, 2000) And these trips have additional difficult effects, such as awakening of psychological problems in the family (Beaverstock et al., 2009).

\subsubsection{Adjustment to a Foreign Culture}

Adjustment to a foreign culture is the degree to which a person feels comfortable in psychological terms with the diverse characteristics of a new environment (Sussman, 2011).

In cases where two cultures fit into the life of one individual, the person can behave in different ways towards the origin culture and the new culture. Berry, Kim, Power and Young. (1989) suggested that there are four main styles of adjustment of acculturation - the absorption of cultural and social customs of another group.

- Assimilation. This describes a situation in which the person's original cultural identity is neglected and he adopts the new culture while becoming more similar to individuals in the new cultural group. In a research of workers on international assignments this is a situation in which the expatriate or businessman attempts to act precisely according to the customs of the foreign country when he interacts with the locals and attempts not to introduce into this interaction elements from his origin culture.

- Integration. The individual retains the main themes of the origin culture but becomes an integral part of the new culture. In relation to the workers on international assignment, this is a situation in which the worker clearly retains the customs that are important to him from the foreign culture but also adopts many customs from the foreign country.

- Separation. The individual retains the cultural identity of his origin country and its customs and refuses to include the new culture. Regarding the research of international assignments, the described situation is interaction characterized by lack of flexibility, on the part of the worker on international assignment. When this worker has business relations in a foreign country, he behaves according to what exists in his culture.

- Marginalization. The individual goes against the new culture and feels he is a stranger in it, is confused in terms of his identity, and experiences tension. In this case, the person loses the cultural and psychological relationship with his origin culture and with the new culture. In the study of workers on international assignment, this is a situation in which the worker, on the one hand, criticizes the foreign culture and refuses its business and cultural practices but, on the other hand, also refrains from the practices of his origin culture.

Berry et al. (1989) differentiated sub-types of adjustment : general adjustment (actions related to everyday life), adjustment to business culture (expressed in the new workplace), adjustment to social attachment (expresses the social system of relationships with the locals in the foreign country), and adjustment to values.

Personality and Adjustment

The literature in the field of psychology suggests that it is possible to map all the personality traits through the Five Factor Model. Extraversion expresses the degree to which a person is communicative, friendly, active, and likes social gatherings .Conscientiousness represents conformity, obedience of rules and procedures, responsibility, organization, and task orientation. Agreeableness is a person's tendency to develop interpersonal relations and to be altruistic and cooperative. Openness expresses openness to new ideas, tolerance of ambiguity, curiosity, and desire to learn .Neuroticism is linked to low emotional stability, agitation, and tendency to mood swings (Huang et al., 2005). 
In addition, research studies have linked the personality characteristics to the level of adjustment to a foreign culture (Huang et al., 2005; Shaffer et al., 2006). Another research found that personality is related directly to adjustment to a new culture, and adjustment is related directly to performances on an international assignment (Lee \& Sukoco, 2008).

In the research studies conducted on populations of expatriates on lengthy international assignments positive relations were found between the characteristics of openness (Huang et al., 2005; Raduan et al., 2010; Shaffer et al., 2006), agreeableness, and extraversion (Caligirui, 2000; Huang et al., 2005; Shaffer et al., 2006) and level of adjustment to a foreign culture. However, established relations were not found between the traits of conscientiousness and neuroticism and the level of adjustment to a foreign culture (Caligiuri, 2000; Huang et al., 2005). These findings are surprising, since these two traits are the strongest predictors of performances at work in general (Barrick \& Mount, 1991).

Till now research studies that examine relationships between personality characteristics and level of adjustment to a foreign culture among workers who take frequent business trips have not been conducted. However, different evidence from studies in the field of business travel may hint at possible directions of relations (Westman, 2004).

Personality and Adjustment - Research Hypotheses

Conscientiousness. In previous studies the expected relations between conscientiousness and adjustment to a foreign culture were not found among expatriates (Caligiuri, 2000; Huang et al., 2005). Since the relationship between adjustment and frequent business trips has not yet been researched, there is basis to believe that in the short international assignments a relation will be found between conscientiousness and adjustment. One reason is that for frequent trips, the worker's living base is in the origin country. While his life routine is filled with changes, the base remains in the familiar country. A second reason relies on the strong relationship between conscientiousness and task orientation, and thus it can be hypothesized that among people who take frequent business trips, which are characterized by the definition of clear tasks and goals (Beaverstock et al., 2009), a relationship will be found between conscientiousness and adjustment.

Hypothesis 1: A positive relationship will be found between conscientiousness and level of adjustment to a foreign culture among travelers on frequent business trips and not among expatriates.

Openness. A worker on international assignment who is high in this index will likely have the desire to learn about the culture of the foreign culture and will less use stereotypes. Previous research studies showed how a person with high cultural openness tends to acclimate better in new environments (Black, 1990). As noted, research studies in the field of expatriate assignment found a positive relationship between openness and adjustment. Cultural openness and openness to new experiences were found to be an essential characteristic also among workers in short assignments (Ornoy \& Tarba, 2013).

Extraversion and agreeableness. Workers on international assignment need to communicate well with the locals in the foreign country so as to understand and learn the new culture (Black, 1990). Extraversion can encourage him to attempt to communicate better with different people related in the everyday life in a foreign country and people who are high in the dimension of agreeableness will attempt to create social relations with the locals. Accordingly, positive relations were found in the research studies between the dimension of extraversion and agreeableness (each separately) and the level of adjustment to a foreign culture among expatriates. Therefore:

Hypothesis 2: A positive relationship will be found between openness, agreeableness, and extraversion (each separately) and the level of adjustment to a foreign culture, both among expatriates and among frequent business trip travelers.

Neuroticism. People with a high level of neuroticism find it difficult to cope with tensions (Buss, 1991). In researches of the expatriate population, a relationship was not found between neuroticism and adjustment; however, in the lengthy assignments this is long-term tension that accompanies expatriates almost without stop for many months (Sussman, 2011). In contrast, in business trips the tension goes up and down, when before every trip there is a considerable rise in the level of tension, after which there is a sharp drop (Westman, 2004). Therefore:

Hypothesis 3: A negative relationship will be found between neuroticism and level of adjustment to a foreign culture among business trip travelers and not among expatriates.

\subsubsection{Gender and Adjustment}

A research that reviewed 25 years of international assignments showed that despite the increase in equality of opportunities for women, the number of women who are recruited for global assignments is still low in comparison 
to the number of men. If in the 1980 s, due to the feminist revolution, the approach that women are as good as men became established, then in the 1990s and 2000s the approaches changed from "women are as good as men" to values of "diversity" in organizations as an essential formula for business success. Accordingly, in the 1990s the number of women who went on assignments overseas increased, but nevertheless their number remained negligible. In the $21^{\text {st }}$ century the trend of increase continues, but the great discrepancy between men and women remains (Altman \& Shortland, 2008). Thus, for example, it was found that in the United States in the 1980s only 3\% of expatriates were women, while in recent years this percentage has increased to 19\% (Ornoy \& Tarba, 2011). On the one hand, this is a significant increase, but on the other hand in this percentage the gender difference is still prominent and apparent.

The Women today, more than ever, report that they are interested in a career and in the management of a family life alongside organizational life. Thus, for example, we will find that among university graduates in Britain no difference was found between the career aspirations of men and women (Altman \& Shortland, 2008). Another research found that there is no relationship between the variable of gender and success at work among expatriates. On the basis of these findings, the researchers recommended to organizations not to attribute importance to the gender during the choice of candidates for international assignments (Selmer \& Lauring, 2011). Therefore:

Hypothesis 4: A difference will not be found in the level of adjustment to a foreign culture between men and women who take part in international assignments.

\section{Method}

\subsection{Participants}

A total of 309 Israeli participants took part in the research, of whom 162 are expatriates in foreign countries on international assignments for at least one year but for no more than eight years $(52.40 \%)$ and 147 are travelers on frequent business trips who take at least five annual trips in the framework of their job (47.60\%). 191 are men $(61.80 \%)$ and 118 women (38.20\%), and 179 are married (57.90\%), 122 single (39.50\%), and 8 are divorced (2.60\%). 112 were managers in the company where they work (36.20\%), 13 are workers $(52.80 \%)$, and 33 are in the category of "other" $(10.70 \%)$. The participants ranged in age from 25-66 (M: 34.90, SD: 9.76), and the duration of time of the stay abroad or in the business trips routine ranged from one year to 30 years (M: 4.58, SD: 4.34). Most of the participants sampled are workers in the hi-tech industry, pharmaceutical industry, and start-ups. The participants were sampled in two stages. In the first stage, acquaintances who met the criteria were sampled. The second stage included recommendations from the participants in the first stage on additional potential participants and their sampling. The subjects participated in the research on a volunteer basis.

\subsection{Instruments}

2.2.1 Personality Questionnaire. The personality characteristics were measured using the Big Five Inventory (BFI) that was composed by John, Donahue, \& Kentle (1991). The questionnaire is composed of 44 items that are in essence different personality characteristics.. The questionnaire is composed of eight items for the dimension of extraversion $(\alpha=0.69)$, nine for the dimension of conscientiousness $(\alpha=0.78)$, nine for the dimension of agreeableness $(\alpha=0.64)$, ten for the dimension of openness $(\alpha=0.72)$, and eight for the dimension of neuroticism $(\alpha=0.78)$. The subjects needed to rank their degree of agreement with the different characteristics as characteristics of their personality on a scale of five levels, when 1 is "strongly disagree" and 5 is "strongly agree".

2.2.2 Adjustment to Foreign Culture Questionnaire. The questionnaire examines the level of adjustment to a foreign culture and is based on the model of Berry et al. (1989). The subjects must note the extent to which they agree with 20 items using a Likert scale from 1 (very slightly) to 5 (very greatly). The questionnaire includes items from four different scales: degree of general adjustment to a foreign country, degree of adjustment to values, degree of adjustment to the new business culture, and degree of adjustment to the social attachment in the foreign country.

The scale of general adjustment includes five items $(\alpha=0.66)$ that examine the extent to which the subject feels comfortable in relation to the actions related to the everyday life, such as speaking in the local language or going shopping locally.

The scale of adjustment to values includes five items $(\alpha=0.73)$ and focuses on the subject's perceived degree of expertise on general topics in the context of the new culture, such as expertise in the political culture or the social culture.

The scale of adjustment to the business culture includes five items $(\alpha=0.66)$ that examine the extent to which the subject feels comfortable in relation to the new business culture, such as the desire to adopt behaviors from it. 
The scale of adjustment to social attachment includes five items $(\alpha=0.79)$ that examine the extent to which the subject feels comfortable with the social system of relations with the locals in the foreign country. For example, the items examine the degree of desire to meet locals outside of the working hours and the preference of relations with Israelis because of the same language and culture. A higher score in the questionnaire items indicates a better level of adjustment (after correction for reversed items).

2.2.3 Socio Demographic Variables Questionnaire. The participants were asked to note basic information - gender, age, and family situation. The variable of country of birth was also used for control purposes, since it can provide an indication of whether the worker has experienced in the past the experience of relocation of residence and adjustment to a new culture.

In addition, the research subjects were asked to answer a number of questions related to their international assignment. For example, what is the frequency of their business trips or how many years did they stay on assignment in the foreign country.

Another variable collected for control purposes is the destination countries to which the workers are going. Since there is very great difference between the subject, it was not possible to control this variable.

\subsection{Process}

With the subject' consent s to participate in the research on international assignments, they were given physically or emailed the research forms appropriate for the group to which they belong - expatriates or frequent business trip travelers. Every subject received one set of questionnaires, which included a preliminary letter, a personality questionnaire, an adjustment questionnaire, and a sociodemographic questionnaire. The personality questionnaire is positioned between the scales of the adjustment questionnaire so as to obscure the research objective. The research subjects were asked to fill out all the questionnaires honestly and to return them upon completion. Complete confidentiality was promised to all participants regarding their responses.

\section{Results}

\subsection{Participants}

Table 1 presents the distributions of the research variables among the participants from both groups (business trip travelers and expatriates) and the differences between them.

Table 1. Descriptive statistics and differences between the groups

\begin{tabular}{lccccccc}
\hline Group & \multicolumn{3}{c}{ Expatriates (N=162) } & \multicolumn{2}{c}{ Travelers (N=147) } & \multicolumn{2}{c}{$\begin{array}{c}\text { Difference between } \\
\text { Groups }\end{array}$} \\
\hline Variable & Range & M & SD & Range & M & SD & \\
\hline Extraversion & $2.13-4.63$ & 3.61 & 0.50 & $2-4.88$ & 3.64 & 0.6 & $\mathrm{t}(286.77)=-0.33$ \\
Neuroticism & $1.25-3.75$ & 2.53 & 0.59 & $1-3.88$ & 2.33 & 0.64 & $\mathrm{t}(307)=2.85^{* *}$ \\
Agreeableness & $2.56-5$ & 3.81 & 0.48 & $2-4.89$ & 3.74 & 0.55 & $\mathrm{t}(307)=0.92$ \\
Conscientiousness & $2.56-5$ & 4.17 & 0.56 & $2.67-5$ & 4.17 & 0.48 & $\mathrm{t}(307)=-0.00$ \\
Openness & $1.80-4.91$ & 3.66 & 0.53 & $2.2-5$ & 3.8 & 0.52 & $\mathrm{t}(307)=-2.43^{*}$ \\
General Adjustment & $1.61-5$ & 3.83 & 0.71 & $1.61-5$ & 3.81 & 0.71 & $\mathrm{t}(307)=0.25$ \\
Adjustment to Values & $1-5$ & 3.38 & 0.73 & $1.41-5$ & 3.37 & 0.77 & $\mathrm{t}(307)=0.12$ \\
Adjustment to Business Culture & $1.40-5$ & 3.27 & 0.71 & $1.80-4.60$ & 3.44 & 0.61 & $\mathrm{t}(307)=-2.26^{*}$ \\
Adjustment to Social Attachment & $1.21-5$ & 3.41 & 0.84 & $1-5$ & 3.48 & 0.88 & $\mathrm{t}(304)=-0.83$ \\
Age & $26-55$ & 34.48 & 10 & $26-55$ & 35.37 & 9.49 & $\mathrm{t}(307)=-0.8$ \\
Gender & 76 Women $(46.9 \%)$ & 42 Women $(28.6 \%)$ & $\chi^{2}(1)=10.98^{* * *}$ \\
Family Situation & 83 Married $(51.2 \%)$ & \multicolumn{9}{c}{96 Married $(65.3 \%)$} & $\chi^{2}(1)=6.26^{*}$ \\
\hline
\end{tabular}

$* \mathrm{p}<0.05,{ }^{* * \mathrm{p}}=0.005, * * * \mathrm{p}<0.001$

Table 1 shows that differences were found between the groups in the variables of neuroticism, openness, and adjustment to business culture. The participants who are business trip travelers were characterized as less neurotic and more open, and their adjustment to the business culture in the foreign country was better, in comparison to the expatriate participants. In addition, differences were found between the groups in gender and in family situation, so that among the travelers there were more men and more married participants than among the expatriates.

Following the relations found between the age, gender, and family situation and the research variables, these variables were controlled in the examination of the research hypotheses. 


\subsection{Examination of Hypotheses 1, 2, and 3}

Table 2 presents the data of the Pearson correlations between the variables in the entire sample.

Table 2. Correlations between research variable

\begin{tabular}{|c|c|c|c|c|c|c|c|c|}
\hline & 1 & 2 & 3 & 4 & 5 & 6 & 7 & 8 \\
\hline 1. Extraversion & - & & & & & & & \\
\hline 2. Neuroticism & $-0.18 * * *$ & - & & & & & & \\
\hline 3. Agreeableness & -0.07 & $-0.19 * * *$ & - & & & & & \\
\hline 4. Conscientiousness & $0.16^{* *}$ & $-0.32 * * *$ & $0.14^{*}$ & - & & & & \\
\hline 5. Openness & $0.34^{* * *}$ & $-0.20 * * *$ & 0.09 & $0.18^{* * *}$ & - & & & \\
\hline 6. General Adjustment & $0.24 * * *$ & $-0.23 * * *$ & 0.02 & $0.22 * * *$ & $0.32 * * *$ & - & & \\
\hline 7. Adjustment to Values & $0.21^{* * *}$ & -0.09 & 0.05 & $0.17^{* *}$ & $0.17 * *$ & $0.30^{* * *}$ & - & \\
\hline 8. Adjustment to Business Culture & $0.13^{*}$ & $-0.18^{* * *}$ & 0.05 & $0.25^{* * *}$ & $0.22^{* * *}$ & $0.30^{* * *}$ & $0.29^{* * *}$ & - \\
\hline 9. Adjustment to Social Attachment & $0.24^{* * *}$ & $-0.13^{*}$ & $0.17 * *$ & $0.17^{* *}$ & $0.34^{* * *}$ & $0.31^{* * *}$ & $0.22^{* * *}$ & $0.17 * *$ \\
\hline
\end{tabular}

${ }^{*} \mathrm{p}<0.05, * * \mathrm{p}<0.005, * * * \mathrm{p} \leq 0.001$

Table 2 shows that many relations were found between the research variables. The traits of extraversion, conscientiousness, and openness were found to be positively related to one another. Conscientiousness was found to be positively related also to agreeableness, while neuroticism was found to be negatively related to all the other traits. All the adjustment scores were found to be related among themselves positively and significantly.

Extraversion, conscientiousness, and openness were found to be positively and significantly related to all adjustment scores. Agreeableness was found to be positively related only to adjustment to the social attachment, while neuroticism was found to be negatively related to general adjustment and to the social and business adjustment.

3.2.1 Hypothesis 1 addressed the interaction between the type of assignment and the trait of conscientiousness on the level of adjustment to a foreign culture. It was hypothesized that there will be a positive relationship between conscientiousness and level of adjustment to a foreign culture among only business trip travelers and not among expatriates.

To examine the hypothesis, four regression analyses were conducted for the four adjustment variables. Each one of the analyses included three steps. In the first step the controlled variables, age, gender, and family situation, were introduced into the model. In the second step the variables of type of assignment and conscientiousness were introduced, and in the third stage the variable of the interaction between the two was introduced.

A unique contribution with marginal significance of the variable of assignment type in the second step was found only in the index of adjustment to the business culture $(\beta=0.1, \mathrm{t}=1.81, \mathrm{p}=0.072)$. As aforementioned, the adjustment to the business culture tended to be higher among the business trip travelers than among the expatriates. In the rest of the indices of adjustment, unique significant contributions of the assignment type were not found $(|\beta|<0.05,|t|<.75$, $\mathrm{p}>0.45$ ).

In all four of the analyses in the second step a significant unique contribution was found of the variable of conscientiousness (general adjustment: $\beta=0.22, t=3.96, p<0.001$; adjustment to values: $\beta=0.19, t=3.33, p=0.001$; adjustment to business culture: $\beta=0.25, \mathrm{t}=4.59, \mathrm{p}<0.001$; adjustment to social attachment: $\beta=0.17, \mathrm{t}=2.89, \mathrm{p}<0.005$ ). In other words, a significant positive relationship was found between conscientiousness and adjustment.

In none of the analyses was a significant difference found in the percentage of the explained variance with the addition of the variable of the interaction to the model $\left(\Delta \mathrm{R}^{2}<0.002, \mathrm{~F}<0.27, \mathrm{p}>0.6\right)$, and a significant unique contribution was not found of the variable of the interaction $(|\beta|<0.03,|t|<0.52, p>0.6)$.

To summarize, in contrast to the hypothesis, interaction was not found between the type of assignment and conscientiousness in the influence on adjustment. A significant positive relationship between conscientiousness and adjustment appeared in the two research groups. This hypothesis was not confirmed.

3.2.2 Hypothesis 2 addressed the interaction between the assignment type and the trait of openness, agreeableness, and extraversion in the level of adjustment to a foreign culture. It was hypothesized that a positive relationship would exist between the three traits and adjustment in the two research groups; in other words, interaction would not be found between the type of assignment and traits.

To examine the hypothesis, 12 regression analyses were conducted, for four variables of adjustment $\mathrm{X}$ three personality traits. Each one of the analyses included three steps. In the first step the control variables were introduced 
into the model. In the second step the variables of assignment type and examined trait (openness, agreeableness, or extraversion) were introduced, and in the third step the variable of the interaction between the examined trait and the assignment type was introduced.

The variable of assignment type made a unique contribution with marginal significance in the second step only in some of the analyses for the prediction of the adjustment to the business culture. (In regression with extraversion: $\beta=0.09, \mathrm{t}=1.68, \mathrm{p}=0.093$, with agreeableness: $\beta=0.1, \mathrm{t}=1.11, \mathrm{p}=0.074$ ). As aforementioned, adjustment to the business culture tended to be higher among business trip travelers than among expatriates. In the rest of the analyses significant unique contributions of this variable were not obtained $(|\beta|<0.09,|t|<1.56, p>0.12)$.

In all four of the analyses that addressed the trait of openness, a significant unique contribution was found in the second step of the variable of openness (general adjustment: $\beta=0.33, t=5.95, p<0.001$; adjustment to values: $\beta=0.18$, $\mathrm{t}=3.12, \mathrm{p}<0.005$; adjustment to business culture: $\beta=0.19, \mathrm{t}=3.42, \mathrm{p}=0.001$; adjustment to social attachment: $\beta=0.33$, $\mathrm{t}=5.98, \mathrm{p}<0.001)$. In other words, a significant positive relationship was found between openness and adjustment.

In none of the analyses was a significant change found in the percentage of the explained variance with the addition of the variable of interaction to the model $\left(\Delta \mathrm{R}^{2}<0.01, \mathrm{~F}<2.73, \mathrm{p} \geq 0.1\right)$, and a significant unique contribution of the variable of interaction was not found $(|\beta| \leq 0.09,|t|<1.66, p \geq 0.1)$.

To summarize, according to the hypothesis, interaction was not found between the type of assignment and openness in the influence on adjustment. A significant positive relationship between openness to adjustment appeared in the two research groups.

A similar picture was obtained in the analyses that addressed the trait of extraversion: in the second step a significant unique contribution of the variable of extraversion was found (general adjustment: $\beta=0.25, \mathrm{t}=4.52, \mathrm{p}<0.001$; adjustment to values: $\beta=0.22, t=3.88, p<0.001$; adjustment to business culture: $\beta=0.14, t=2.63, p<0.01$; adjustment to social attachment: $\beta=0.24, \mathrm{t}=4.36, \mathrm{p}<0.001)$. In other words, a significant positive relationship was found between extraversion and adjustment.

In none of the analyses was a significant change found in the percentage of explained variance with the addition of the variable of interaction to the model $\left(\Delta \mathrm{R}^{2}<0.01, \mathrm{~F}<2.52, \mathrm{p}>0.11\right)$. A significant unique contribution of the variable of interaction was not found $(\beta \leq 0.09, \mathrm{t}<1.59, \mathrm{p}>0.11)$.

To summarize, according to the hypothesis, interaction was not found between the type of assignment and extraversion in the influence on the adjustment. A significant positive relationship between extraversion and adjustment appeared in the two research groups.

In analyses that addressed the trait of agreeableness a slightly different picture was obtained. In the analysis for the prediction of the index of adjustment to social attachment the hypothesized result was obtained. Agreeableness made a significant and positive unique contribution to the prediction of the adjustment in the second step $(\beta=0.18, t=3.17$, $\mathrm{p}<0.005$ ), while the addition of the variable of interaction to the model did not increase the percentage of the explained variance $\left(\Delta \mathrm{R}^{2}=0.00, \mathrm{~F}(1,299)=0.07, \mathrm{p}>0.05\right)$, and the variable of the interaction itself did not make a significant unique contribution $(\beta=0.01, \mathrm{t}=0.26, \mathrm{p}>0.05)$.

In other words, according to the hypothesis, a positive relationship was found between agreeableness and adjustment to social attachment without dependence on the assignment type.

In contrast, in the analyses that addressed the general adjustment score and adjustment to values in the foreign country a significant unique contribution of agreeableness was not found in the second step $(\beta<0.07, t<1.07, p>0.28)$. In these analyses, too, a significant increase in the explained variance was not found in the third step $(\Delta \mathrm{R} 2<0.01$, $\mathrm{F}<1.6, \mathrm{p}>0.2)$, and a significant unique contribution of the variable of the interaction was not found $(|\beta|<0.08$, $|\mathrm{t}|<1.27, \mathrm{p}>0.2)$.

In other words, in contrast to the hypothesis, a relationship was not found between agreeableness and general adjustment and adjustment to values, regardless of the type of assignment.

A surprising finding was obtained in the analysis that addressed the adjustment to the business culture. In this analysis, too, a significant unique contribution of agreeableness in the second step was not found $(\beta=0.08, t=1.45$, $\mathrm{p}>0.15)$, but a significant increase in the explained variance was found in the third step $\left(\Delta \mathrm{R}^{2}=0.02, \mathrm{~F}(1,302)=5.67\right.$, $\mathrm{p}<0.05)$, and a significant unique contribution was found of the variable of the interaction $(\beta=-0.13, t=-2.38$, $\mathrm{p}<0.05)$.

So as to identify the source of the interaction partial correlations were calculated (with control of the age, the gender, and the family situation) between agreeableness and adjustment to the business culture in each one of the two groups 
separately. A significant positive relationship was found between agreeableness and adjustment to the business culture among expatriates $(\mathrm{r}=0.18, \mathrm{p}<0.05)$ but not among business trip travelers $(\mathrm{r}=-0.7, \mathrm{p}>0.05)$.

In other words, in contrast to the hypothesis, agreeableness was found to be positively related to adjustment to the business culture only among expatriates.

To conclude, this hypothesis was completely confirmed regarding openness and extraversion and partially confirmed regarding agreeableness.

3.2.3 Hypothesis 3 addressed the interaction between the assignment type and the trait of neuroticism on the level of adjustment to a foreign culture. It was hypothesized that there would be a negative relationship between neuroticism and level of adjustment to a foreign culture among only business trip travelers and not among expatriates.

To examine the hypothesis, four regression analyses were conducted for the four variables of adjustment. Each one of the analyses included three steps. In the first step the control variables were introduced into the model, in the second step the variables of the assignment type and neuroticism were introduced, and in the third step the variable of the interaction between the two was introduced.

A significant unique contribution of the variable of assignment type was not found in the second step in any of the four analyses $(|\beta|<0.09,|t|<1.52, \mathrm{p}>0.13)$.

In analyses that addressed the general adjustment, adjustment to business culture, and adjustment to social attachment, in the second step a unique contribution with significance or marginal significance was found for the variable of neuroticism (general adjustment: $\beta=-0.22, t=-3.72, p<0.001$; adjustment to business culture: $\beta=-0.12$, $\mathrm{t}=-2.1, \mathrm{p}<0.05$; adjustment to social attachment: $\beta=-0.11, \mathrm{t}=-1.88, \mathrm{p}=0.62$ ). In other words, a negative relationship was found between neuroticism and adjustment.

In contrast, in the analysis that addressed adjustment to values a significant unique contribution of the variable of neuroticism was not found $(\beta=-0.09, \mathrm{t}=-1.46, \mathrm{p}>0.05)$. In other words, a significant relationship between neuroticism and adjustment to values was not found.

In the analyses that addressed the general adjustment, adjustment to values, and adjustment to business culture, a significant change was not found in the percentage of the explained variance with the addition of the variable of the interaction to the model $\left(\Delta \mathrm{R}^{2}<0.01, \mathrm{~F}<2.4, \mathrm{p}>0.12\right)$, and a significant unique contribution of the variable of the interaction was not found $(\beta<0.09, \mathrm{t}<1.55, \mathrm{p}>0.12)$.

In contrast, in the variable of adjustment to social attachment, a change in the percentage of the explained variance was found with the introduction of the variable of interaction into the model $\left(\Delta \mathrm{R}^{2}=0.02, \mathrm{~F}(1,299)=5.52, \mathrm{p}<0.05\right)$ and a significant unique contribution was found of the variable of the interaction $(\beta=-0.13, \mathrm{t}=-2.35, \mathrm{p}<0.05)$.

To identify the source of the interaction, partial correlations were calculated (after controlling the demographic variables) between neuroticism and adjustment to social attachment in each one of the two groups separately. According to the hypothesis, a significant negative relationship was found between neuroticism and adjustment to social attachment among business trip travelers $(\mathrm{r}=-0.22, \mathrm{p}<0.01)$ but not among expatriates $(\mathrm{r}=-0.01, \mathrm{p}>0.05)$.

To conclude, neuroticism was found to be negatively related to general adjustment and to business culture adjustment in the two research groups, but it was not found related at all to adjustment to values and was found to be related to adjustment to social attachment only among travelers. This hypothesis was confirmed regarding adjustment to social attachment but not regarding the other measures of adjustment.

\subsection{Examination of Hypothesis 4}

To examine hypothesis $\mathbf{4}$, the relationship between gender and adjustment was examined, through t-tests for independent samples, to compare between men and women in the four measures of adjustment. The findings are presented in Table 3.

Table 3. Adjustment to foreign culture among men and women

\begin{tabular}{lccccc}
\hline Gender & \multicolumn{2}{c}{ Men (N=191) } & \multicolumn{2}{c}{ Women (N=118) } & Difference between Groups \\
\hline Variable & M & SD & M & SD & t \\
\hline General Adjustment & 3.89 & 0.68 & 3.71 & 0.73 & $\mathrm{t}(307)=2.35^{*}$ \\
Adjustment to Values & 3.42 & 0.80 & 3.31 & 0.66 & $\mathrm{t}(282.11)=1.34$ \\
Adjustment to Business Culture & 3.46 & 0.62 & 3.17 & 0.71 & $\mathrm{t}(307)=3.75^{* * *}$ \\
Adjustment to Social Attachment & 3.50 & 0.87 & 3.34 & 0.84 & $\mathrm{t}(304)=1.55$ \\
\hline
\end{tabular}

$* \mathrm{p}<0.05,{ }^{* * *} \mathrm{p}<0.001$ 
As can be seen in Table 3, the scores of general adjustment and adjustment to the business culture were found to be higher among men than among women. In other words, in contrast to the hypothesis, a difference was found between gender and the two measures of adjustment to foreign culture, according to which men adjust better to everyday life in a foreign country and to the business culture.

In the continuation, the possibility of interaction between the type of assignment and gender, in the influence on adjustment, was examined. To examine this, four regression analyses were conducted for the four variables of adjustment. Each one of the analyses included two steps. In the first step the variables of gender and type of assignment were introduced into the model, in the second step the variable of interaction between the assignment type and gender was introduced. The steps were performed in the stepwise method that is suitable for an exploratory analysis of this type. Significant interactions between type of assignment and gender in the influence on adjustment were not found.

\section{Discussion}

In the present research we chose to examine the topic of adjustment to a foreign culture and how the characteristics of personality and gender influence it.

Regarding relationships examined between the personality characteristics and measures of adjustment, it is possible to say that regardless of the other characteristics (such as type of assignment), all the personality characteristics were found to be related to adjustment to the foreign culture (extraversion, conscientiousness, and openness were found related to all the measures of adjustment, while neuroticism and agreeableness were found related to some of the adjustment measures). This finding shows the strong relationship that has already been proven in previous studies between personality characteristics and adjustment (Huang et al., 2005; Shaffer et al., 2006). In addition, all the measures of adjustment to a foreign culture were found related to one another in significant positive relationships but in lower than expected correlations. It was further found that in general business trip travelers were found to be more open and less neurotic and to have better adjustment to the business culture.

In addition, among the subjects in the group of business travelers there were more men and more married people. These findings are commensurate with the different nature of the assignments. It is reasonable that women commit less to positions that entail many trips, since the assignments force them to leave their families. In addition, single participants can adjust more to the expatriate assignment since they are not uprooting an entire family from its home country but are moving themselves for a number of years to live in a foreign country.

In hypothesis 1 we hypothesized that only among business trip travelers would a positive relationship be found between conscientiousness and adjustment to a foreign culture. This hypothesis was not confirmed, since in both groups, expatriates and business trip travelers, this relationship was found. In other words, conscientiousness predicted success in adjustment, in all four of the dimensions examined, regardless of the type of international assignment. This finding supports the research of Raduan et al. (2010), in which analysis of the findings presents a positive relationship between conscientiousness and adjustment among expatriates but contradicts other works (Caligiuri, 2000; Huang et al., 2005) in which this relationship was not found. While the findings of our research on the strong relationship between conscientiousness and adjustment also among expatriates do not completely fit with different studies in the field of expatriate assignments, this evidence supports other research studies from the field of the personality. In the framework of these researches, conscientiousness, in comparison to the other personality characteristics, was found to be the most strongly related to performances at work (Barrick \& Mount, 1991). Therefore, it is not impossible that traits such as responsibility, organization, and perseverance, which characterize more conscientious people, contribute to the adjustment to a foreign culture, regardless of the type of assignment. So as to attempt to bridge the gap between the research studies in the field of personality and research studies in the field of international assignments, a continuation research can use a number of different instruments for the measurement of adjustment, since the diverse research studies that examined the level of adjustment used different research instruments.

We divide the discussion of the findings of hypothesis 2 into two parts. One part is reference to the characteristics of openness and extraversion, and the second part is reference to the characteristic of agreeableness, according to the patterns of the different results that were obtained.

First, and according to the hypothesis, better adjustment, in all four measures, was found to be linked to high levels of openness and extraversion (each separately), regardless of the type of adjustment, among expatriates and business travelers. Therefore, and like the effect obtained also in the context of the characteristic of extraversion, both in the group of expatriates and in the group of business travelers, as a higher level of openness or extraversion is observed, 
a higher level of adjustment to foreign culture was identified. These findings support the findings of previous research studies (Huang et al., 2005; Shaffer et al., 2006).

In the context of the dimension of openness, another interesting finding in our research is that in general frequent business trip travelers show higher levels of openness than do expatriates. The travelers on frequent business trips still pass through many more and more diverse cultures, since the life of the business traveler is characterized by different trips, for the most part to different countries each time, when they are required to have considerable openness - both culturally and in terms of a routine of life that is not stable. Therefore, it is likely that a worker or manager who is not gifted with a high level of openness cannot continue with the performance of the short assignments every time. It is clear that an expatriate cannot function without a high level of openness but, to differentiate from a business trip traveler, the expatriate can learn the new culture and make it from strange to familiar, since his life is managed now in its framework.

In contrast to the characteristics of openness and extraversion, which predicted the level of adjustment in the two populations and fit the hypothesis, in the context of the characteristic of agreeableness a more complex picture was found, which we describe now.

First, according to the hypothesis, a significant positive relationship was found between agreeableness and adjustment to social attachment in the two research populations - expatriates and business travelers. This relationship between agreeableness and this specific type of adjustment is easily explained since the nature of the dimension of agreeableness is the person's ability to develop interpersonal relations.

However, in contrast to our hypothesis, a relationship was not found between the dimension of agreeableness and general adjustment and adjustment to values in any one of the research groups. This finding is contradictory to previous research studies that found a relationship between general adjustment and agreeableness (Caligiuri, 2000; Huang et al., 2005; Shaffer et al., 2006) but is commensurate with the research of Raduan et al. (2010) where this relationship was not found. Therefore, we suspect that agreeableness is related more to interpersonal relations and less to adjustment to everyday life in a foreign country.

The last measure of adjustment, adjustment to the business culture, brought the most interesting and surprising finding in the context of the characteristic of agreeableness. Our research found a positive relationship between agreeableness and adjustment to the business culture only among expatriates. This finding is especially prominent in light of another finding, an opposite finding, that was obtained in our research, according to which, in general and regardless of any relationship to the personality characteristics, business trip travelers adjust better to the business culture in comparison to expatriates. Regarding all the rest of the measures of adjustment (general adjustment, value adjustment, and social adjustment) and eliminating additional characteristics such as personality characteristics, a difference was not found between the group of expatriates and the group of business travelers. Only adjustment to the business culture showed an advantage to the population of travelers. However, this advantage not only disappeared but also changed direction, when the personality variable of agreeableness was taken into consideration. A possible explanation is that business travelers who are high in the dimension of agreeableness tend to invest time in the construction of social systems of relations in the different countries to which they go and these actions take resources from the adjustment to the business environment. It is not impossible that expatriates who are found for the most part in one country in the framework of a specific assignment have more time and thus can build social relations. Therefore, it is possible that the expatriates can focus both on the creation of social relations and on the familiarity with the business culture, for a lengthy period of time. In contrast, business trip travelers have a short and limited time in each country, and therefore those with a high level of agreeableness, who have a strong social orientation, may focus greatly on the social relations at the expense of other elements. In addition, certain cultures can see agreeable people as trying or pushing too hard (Raduan et al., 2010)..

Hypothesis 3 examined the relationship between the characteristic of neuroticism and the level of adjustment. In this case too, a complex picture was obtained.

It was found that neuroticism is negatively related to adjustment to social attachment only among business travelers. However, general adjustment and business adjustment were found to be negatively related not only to the group of business travelers but also to the group of expatriates. In other words, the assignment type was not important in the relationship between general and business adjustments and neuroticism. This finding is commensurate with the findings of Shaffer et al. (2006), who found in their research a negative relationship between adjustment and neuroticism among expatriates, but is contradictory to the findings of other studies (Caligiuri, 2000; Huang et al., 2005; Raduan et al., 2010), which did not find any relationship between neuroticism and adjustment among expatriates. 
A relationship was not found between neuroticism and adjustment to values in a foreign country. As aforementioned, this finding, too, agrees with the findings of other works, although they hypothesized relationships between neuroticism and adjustment but did not find them in actuality. People with a high level of neuroticism find it difficult to cope with tensions (Buss, 1991), when tension is linked with ambiguity and foreignness, which are characteristics of global assignments .This difficulty greatly influences adjustment to a foreign culture, but it is not impossible for its influence to be expressed primarily in everyday actions. Of the four measures of adjustment, adjustment to values is the most philosophical index, entailing more thoughts and beliefs than actions. To confirm this hypothesis, a future research can examine the adjustment to values not only in philosophical terms but also in terms of behavioral intention.

Another finding of our research showed that business travelers show in general lower levels of neuroticism compared to expatriates. As we noted, the short trips entail many tensions, which increase and subside, when each time the worker only has a short time to learn about the country and about the assignment. In the case of long expatriate assignments, the worker has more time to learn about the new culture, to know it beforehand, and to prepare for his arrival, and thus, in essence, the future expatriate can reduce to a certain degree the unexpected elements that will characterize his new life. Regarding the appointment of workers to international assignments, for the most part, positions that entail many short trips outside of the country are defined as such ahead of time (Westman, 2004). In contrast, frequently workers are chosen for expatriate assignments from an existing local position that they have held for a certain period (Sussman, 2011). Therefore, it is possible that people with high levels of neuroticism from the beginning will apply for a position that entails many trips but will apply for a position that might over time become an international assignment.

Regarding hypothesis 4, a difference was found in the level of adjustment between men and women, in contrast to our expectations. The results of our research indicate that men, in comparison to women, adjust better regarding two of the four measures of adjustment examined here: general adjustment and adjustment to the business culture. In the other two types of adjustment, adjustment to values and adjustment to social attachment, a difference between the genders was not found. In an era in which many women develop careers, like men do, it is surprising to obtain such a finding, which seemingly describes a gender advantage for men in the performance of international assignments.

Women frequently find themselves divided between focus on their career and business success and family commitment. Therefore, the acceptable explanation is that women, unlike men, invest a large part of their resources in the family as well, and it is not impossible that these resources come at the expense of the learning of the local business culture. Although there is a rise in the involvement of women in the job market in general and in their involvement in international assignments in particular (Altman \& Shortland, 2008).

Aside from this complexity, there frequently are difficulties with the values and customs from the country of origin, which may set before women obstacles in the adjustment to the business culture. For instance, women from cultures with traditional values may find it difficult to adjust to an assertive and masculine business environment .Conversely, women from Western cultures, such as Israeli culture, may encounter difficulties adjusting to the business culture and everyday life in certain countries in South America or Asia, since in these countries prejudices against women are relatively more widespread (Ornoy \& Tarba, 2011). A future research can attempt to clarify the issue by sampling women and men who are on international assignments in only Western cultures versus women and men who are on international assignments in Eastern/traditional cultures.

Until now we have presented possible explanations why adjustment among women in our research was found to be less good than that of men. However, there are research studies that present a different picture. The research of Selmer and Lauring (2011) found that there is no difference between the performance of men expatriates and that of women expatriates (as noted, there is a relationship between adjustment and performances and success on the assignment). Moreover, the research of Cole and McNulty (2011) not only did not find male superiority in terms of adjustment but also showed a slight advantage in adjustment among women.

In addition, it is important to take into consideration the possibility that the self-reports of the women in the research were more modest compared to those of the men, not necessarily because of difficulties with adjustment but because of differences in gender tendency. This explanation is commensurate with research studies from the field of gender (such as Wilson, Kickul, \& Marlino, 2007), which found that men are characterized by higher self-efficacy. Therefore, it is not impossible that men believe more in their ability to adjust in comparison to women, who ahead of time display lower self-efficacy. 


\subsection{Research Limitations and Advantages}

Our research found a very great difference in the countries to which the research subjects were sent. This great difference did not allow us to control for the variable of country/culture, and therefore many questions remain open regarding the cultural influence on the level of adjustment among the workers.

In our research we used self-reporting questionnaires, which, are open biases, such as social desirability. So as to broaden the objectivity of the report and the understanding of the subjects' adjustment, a continuation research can acquire data from additional factors, such as work colleagues, superiors, and even family members.

Last, we addressed in our research the issue of adjustment, but it is not the only criterion for the success of the international assignment. Additional criteria, such as business performances, worker satisfaction, and organizational commitment also may have influence on the success of the assignment. Future research works can examine them in a comparative manner between the two types of assignments.

Along with the research limitations, it is possible to indicate a number of prominent advantages. Although not all the research hypotheses were confirmed, this is still a pioneer study that compares for the first time between the two types of global assignments - expatriate positions and frequent business trips. This research is also among the first studies, if it is not the first, to examine the relationship between personality and adjustment among workers who take part in frequent business trips. Now, on the basis of the initial findings of the present research, additional works can continue to examine these and other relationships.

In addition, these are also initial findings on the direct relationship between gender and adjustment in the international arena, according to which there is a gender advantage to men in certain measures of adjustment to a foreign culture. While they are not the findings we had aspired to ideologically, nevertheless it is necessary to recognize that they exist and to think how it is possible to reduce the gaps, so as to enable the equality of opportunity for women who take part in the world of global organizations.

\section{References}

Altman, Y., \& Shortland, S. (2008). Women and international assignments: Taking stock A 25 year review. Human Resource Management, 47(2), 199-216. http://dx.doi.org/10.1002/hrm.20208

Barrick, M., \& Mount, M. (1991). The Big Five personality dimensions and job performance. Personnel Psychology, 44, 1-26. http://dx.doi.org/10.1111/j.1744-6570.1991.tb00688.x

Beaverstock, J., Derudder, B., Faulconbridge, J., \& Witlox, F. (2009). International business travel: Some explorations. Human Geography, 91(3), 193-202.

Berry, J. W., Kim, U., Power, S., \& Young, M. (1989). Acculturation attitudes in plural societies. Applied Psychology: An International Review, 38(2), 185-206. http://dx.doi.org/10.1111/j.1464-0597.1989.tb01208.x

Black, J. S. (1990). The relationship of personal characteristics with the adjustment of Japanese expatriate managers. Management International Review, 30(2), 119-34.

Buss, D. M. (1991). Evolutionary personality psychology. Annual Review of Psychology, 42, 459-491. http://dx.doi.org/10.1146/annurev.ps.42.020191.002331

Caligiuri, P. M. (2000). The Big Five personality characteristics as predictors of expatriate's desire to terminate the assignment and supervisor rated performance. Personnel Psychology, 53, 67-88. http://dx.doi.org/10.1111/j.1744-6570.2000.tb00194.x

Cole N., \& McNulty Y. (2011). Why do female expatriates "fit-in" better than males? An analysis of self-transcendence and socio-cultural adjustment. Cross Cultural Management: An International Journal, 18(2), 144-164. http://dx.doi.org/10.1108/13527601111125996

DeFrank, R. S., Konopaske, R., \& Ivancenich, J. M. (2000). Executive travel stress: perils of the road warrior. Academy of Management Executive, 14(2), 58-71.

Demel, B., \& Mayrhofer, W. (2010). Frequent business travelers across Europe: Career aspirations and implications. Thunderbird International Business Review, 52(4), 301-311. http://dx.doi.org/10.1002/tie.20352

Digman, J. M. (1997). Higher-order factors of the big five. Journal of Personality and Social Psychology, 73, 1246-1256. http://dx.doi.org/10.1037/0022-3514.73.6.1246

Harvey, M., \& Novicevic, M.M. (2001). Selecting expatriates for increasingly complex global assignments. Career Development International, 6(2), 69-87. http://dx.doi.org/10.1108/13620430110383357 
Huang, T.J., Chi, S. C., \& Lawler, J. (2005). The relationship between expatriates' personality traits and their adjustment to international assignments. International Journal of Human Resource Management, 16(9), 1656-1670. http://dx.doi.org/10.1080/09585190500239325

John, O. P., Donahue, E. M., \& Kentle, R. I. (1991). The "Big Five” Inventory-Versions 5a and 54. Technical Report. Berkeley: University Institute of Personality and Social Psychology.

Lee, L.Y., \& Sukoco, B.M. (2008). The mediating effects of expatriate adjustment and operational capability on the success of expatriation. Social Behavior and Personality, 36(9), 1191-1204. http://dx.doi.org/10.2224/sbp.2008.36.9.1191

Morley, M., \& Heraty, N. (2004). International assignments and global careers. Thunderbird International Business Review, 46, 633-646. http://dx.doi.org/10.1002/tie.20028

Ornoy, H., \& Tarba, S. (2011). The effects of situational and personal factors on an employee motivation for relocation. Global Business and Economics Review, 13(3/4), 257-268. http://dx.doi.org/10.1504/GBER.2011.041851

Raduan, C. R., Subramaniam, S. R., Jegak, U., \& Naresh, K. S. (2010). Expatriate performance in overseas assignments: The role of big five personality. Asian Social Science, 6(9), 1911-2017.

Selmer, J., \& Lauring J. (2011). Marital status and work outcomes of self-initiated expatriates: Is there a moderating effect of gender? Cross Cultural Management: An International Journal, 18(2), 198-213. http://dx.doi.org/10.1108/13527601111126021

Shaffer, M. A., Harrison, D. A., Gilley, K. M., \& Luk, D. M. (2001). Struggling for balance amid turbulence on international assignments: Work-family conflict, support and commitment. Journal of Management, 27, 99-121. http://dx.doi.org/10.1177/014920630102700106

Shaffer, M. A., Harrison, D. A., Gregersen, H., Black, J. S., \& Ferzandi, L. A. (2006). You can take it with you: Individual differences and expatriate effectiveness. Journal of Applied Psychology, 91(1), 109-125. http://dx.doi.org/10.1037/0021-9010.91.1.109

Sussman, N. M. (2011). Working abroad and expatriate adjustment: Three disciplinary lenses for exploring the psychological transition cycle of international employees. Social and Personality Psychology Compass, 5(7), 393-409. http://dx.doi.org/10.1111/j.1751-9004.2011.00361.x

Tay, C., Westman, M., \& Chia, A. (2008). Antecedents and consequences of cultural intelligence among short-term business travelers. In S. Ang \& L. Van Dyne (Eds.), Handbook of cultural intelligence: Theory, measurement, and applications (pp.126-144). New York, NY: M. E. Sharpe.

Westman, M. (2004). Strategies for coping with business trips: A qualitative exploratory study. International Journal of Stress Management, 11(2), 167-176. http://dx.doi.org/10.1037/1072-5245.11.2.167

Wilson, F., Kickul, J., \& Marlino, D. (2007). Gender, entrepreneurial self-efficacy, and entrepreneurial career intentions: Implications for entrepreneurship education. Entrepreneurship Theory and Practice, 31(3), 387-406. http://dx.doi.org/10.1111/j.1540-6520.2007.00179.x 